\title{
Influence of inflation on long-term economic growth in the context of the raw material orientation of the national economy
}

\author{
Aizhan Omarova ${ }^{1, *}$, Zhanar Oralbaeva ${ }^{1}$, Assel Turlybekova ${ }^{1}$, Assiya Marat $^{1}$ \\ ${ }^{1}$ Al-Farabi Kazakh National University, al-Farabi Ave. 71, 050040 Almaty, Kazakhstan
}

\begin{abstract}
In modern conditions for Kazakhstan, it becomes important to choose a development model that would be the most optimal and effective. When developing a model of economic policy, special attention should be paid to the choice of a system of indicators that could adequately describe macroeconomic processes as a whole and their interconnections. At the same time, economists argue that the implementation of the model approach can become the basis for strategic decisions only in a stable economic situation and when in the period under review the change in the cost structure of GDP is not distorted by high inflation. Therefore, in modern conditions of economic development, in our opinion, it is of interest to study the relationship between economic growth and the level of current and threshold inflation. This study substantiates the role of the threshold inflation level and proposes an equation of the functional dependence of this indicator on the main economic indicators. The necessary conditions for the implementation of the inflation targeting regime are disclosed. It is concluded that in conditions of commodity dependence, new effective monetary policy instruments are required.
\end{abstract}

\section{Introduction}

The raw materials orientation of the national economies of the countries exporting raw materials affects the level of inflation, which, in turn, has a certain effect on economic growth. In particular, at the end of the 70s of the last century, the Dutch economist, Nobel Prize winner Jan Tinbergen, as a result of his research, revealed the "Groningen effect", which is an objective phenomenon in the economic development of countries with significant raw material resources. He examined in detail the mechanism of the effect of this effect on the level of inflation in the country.

According to the scientist, a large reserve of natural resources provides significant opportunities for the development of the country, but also carries a number of dangers.

The abundance of natural raw materials can cause a certain increase in a specific factor of production. And high world prices for raw materials, in particular for fuel and energy resources, provoke an increase in their exports. The commodity sector begins to develop rapidly. As a result, a serious influx of foreign currency into the country begins. This leads

\footnotetext{
* Corresponding author: a.omarova776@gmail.com
} 
to the strengthening of the national currency, which is not supported by the growth of production. Negative effects are beginning to appear: the entire comparative advantage is moving to the raw materials sector - investments, high-quality labor resources, high salaries.

Domestic manufacturing products are becoming less competitive in both the foreign and domestic markets. The consumer switches to imported counterparts. Structural changes are beginning in the country's economy (the growth of raw materials industries and the decline of non-raw materials). Salary growth and commodity income triggers price increases and inflation. As a result, there is a slowdown in the economy of the whole country: the higher the share of energy exports, the more global the problems in the economy.

It is important to note that commodity markets are particularly prone to volatility. This creates a strong macroeconomic instability. In a period of high prices, the national currency appreciates and exacerbates the "Dutch disease". After a fall in prices, the trade balance worsens and the national currency devalues, causing a surge in inflation [1].

This is the mechanism of the Groningen effect. Thus, when it comes to the Groningen effect, first of all, it implies an increase in the real exchange rate due to an increase in the export volumes of some industries, which has a negative impact on other industries and the economy as a whole. Undoubtedly, mining is such a sector for Kazakhstan.

\section{Results and Discussion}

One of the negative effects of inflation is its instability. The volatility of inflation leads to an uncertain price level in the economy. At the moment, the influence of external economic factors on inflation in Kazakhstan has intensified; this effect can be traced through the mechanism of cost inflation. Cost inflation associated with a decrease in aggregate supply has a negative effect on the gross domestic product, leads to a decrease in business activity in the country and slows down the rate of economic growth. When analyzing the impact of various external economic factors, the conclusion was made: our country is highly dependent on the global economic situation, primarily on world prices for energy resources. The following logical chain can be traced: a decrease in world energy prices entails a devaluation of tenge and a relative rise in price of imported goods and factors of production. This, in turn, leads to a decrease in the purchasing power of the population and to a decrease in the business activity of firms using imported resources in the production process. All this negatively affects the rate of economic growth, which leads to the flight of capital from the country, even greater inflation and lower investment activity [2]. Thus, it is Kazakhstan's excessive dependence on commodity markets that causes the growth of cost inflation and hinders the economic development of our country. However, a completely different point of view prevails among economists, stating that inflation in Kazakhstan is associated primarily with excess aggregate demand, insufficient commodity supply and excessively high growth rates of household incomes. In such circumstances, it seems necessary to take measures to curb aggregate demand through tight monetary policy in order to restrain inflation and ensure economic growth.

Moreover, A. Nurzhigitova claims that the main reason for the ineffectiveness of the methods of regulating inflationary processes in Kazakhstan is the imbalance of the economy, the peculiarity of the structure of which is reflected in the weak development of the production of consumer goods both during the planned economy and now in the conditions of the raw material orientation of the economy. In her opinion, income from the export of raw materials creates an additional supply in the foreign exchange market, which in turn leads to a strengthening of tenge. If the National Bank tries to restrain the increase in the real tenge exchange rate by intervening in the foreign exchange market, the money supply is expanding and inflation is rising. Large revenues from mineral exports, weakening and delaying the 
implementation of the necessary structural reforms in the economy in the country. Therefore, the reform of the economy, aimed at deep processing of raw materials, able to absorb the country's monetary resources is effectively proceeding at a slow pace.

The raw materials export orientation of the country's economy can exacerbate macroeconomic imbalances in the country, but at the same time accelerate the creation of a full-fledged infrastructure of a market economy, provided that export revenues are effectively managed. At the same time, the efforts of the state should be aimed at a justifiable redistribution of export revenues in order to create the prerequisite for the economic recovery of the non-resource sector, since limited natural resources determine the temporary nature of export revenues [3].

In this paper, we examine the effect of inflation on economic growth and the effectiveness of monetary policy in the long-term period.

The problem of the influence of inflation on economic growth has been the subject of many scientific papers. In particular, A. Illarionov, as a result of his research, came to the conclusion "that inflation negatively affects economic growth. This means that, ceteris paribus, the higher the heat of inflation, usually lower than the rate of economic growth. The critical level of annual inflation, above which, for the main groups of countries stops economic growth and begins an economic downturn, is the average annual inflation rate of $25-49 \%$. The critical rate of inflation, that is, the level below which the maximum rates of economic growth are achieved, and then there is a decrease, is the average annual rate of inflation in the range 1.1-4.7" [4].

Nobel laureate J. Stiglitz stresses the assertion that "inflation has a negative effect on economic growth" is erroneous that "below a certain critical level - this threshold level is much higher than the inflation rates that prevail in Europe and North America - there is no evidence of the significant negative impact of inflation" [5].

Moreover, studies by another Nobel laureate J. Akerlof show that suppressing inflation too much can inhibit economic growth, especially during structural changes [6].

According to many studies, different countries with the same level of current inflation will have different rates of economic growth, this will depend on the threshold inflation level and vice versa. Such conclusions were made in the work of K.B. Beretayev, he justified the necessary conditions for achieving sustainable economic growth [7].

Therefore, in order to achieve sustainable economic growth, it is necessary to determine inflation thresholds for each individual country and for Kazakhstan in particular.

As it is known, the relationship between economic growth and changes in inflation is described by the following formula:

$$
\Delta \mathrm{X}=\frac{\Delta \mathrm{Y}-\Delta \mathrm{P}}{1-\Delta \mathrm{P}}
$$

where:

$\mathrm{X}-$ real GDP;

$\mathrm{Y}-$ the nominal GDP;

$\mathrm{P}$ - the price index.

It is clear that there is a critical inflation rate $-\rho *=\mathrm{dP} *$, at which the economic growth rate is $\dot{\eta}=\mathrm{dX}=0$. This inflation rate is called the "threshold". Using the threshold inflation rate, you can determine in which period there will be a direct and inverse relationship between economic growth rates and inflation.

It is known that the relationship between economic growth rates and threshold and current inflation values is determined by relations of the form:

where:

$$
\grave{\eta}=\left(\rho_{1}-\rho\right) /(1+\rho)
$$


$\rho$ - current inflation rate;

$\rho_{1}-$ threshold inflation rate [4].

It should be noted that relation (2) is true for an economy that is in a period of cyclical decline or economic growth. Therefore, it can be argued that the necessary condition for ensuring economic growth is to maintain the current inflation rate at a level lower than its threshold value $\rho *$.

The result of the study of Polterovich V. M (2006) is that threshold inflation for developing countries is $10 \%$, and for developed countries these indicators are lower [8]. Other studies related to the impact of inflation on economic growth calculate threshold inflation as the critical level of inflation, above which it begins to negatively affect economic growth. In studies of Espinoza R. (2010), these critical values for developed countries are $1 \%$, and for developing countries $11 \%$ [9]. In Kremer (2013), these values are $2.5 \%$ and about $17 \%$, respectively. In recent works devoted to determining the relationship between inflation and economic growth, not only the threshold values for inflation are estimated, but also factors that affect the threshold level are analyzed [10]. So, in the work ofEggoh, Khan, (2014), based on the analysis of the dynamic model, the authors concluded that they are more prone to high inflation in a country with a developed financial system and open economy. In addition, the results of these studies confirmed that the lower threshold inflation in developed countries depends on the development of the financial system and the quality of institutions [11]. According to these studies, it can be concluded that inflation below the threshold level does not affect economic, and in some cases it affects positively, stimulating production. If inflation rates exceed the threshold level, then a further increase negatively affects long-term economic growth. Such a conclusion, in essence, contradicts the classical postulate of "neutrality of money" and emphasizes the role of monetary policy, which affects the real output of both the short-term and the long-term.

In this article, based on statistics from 2000 to 2018, we tried to determine the relationship between changes in GDP and inflation in Kazakhstan (Figure 1).

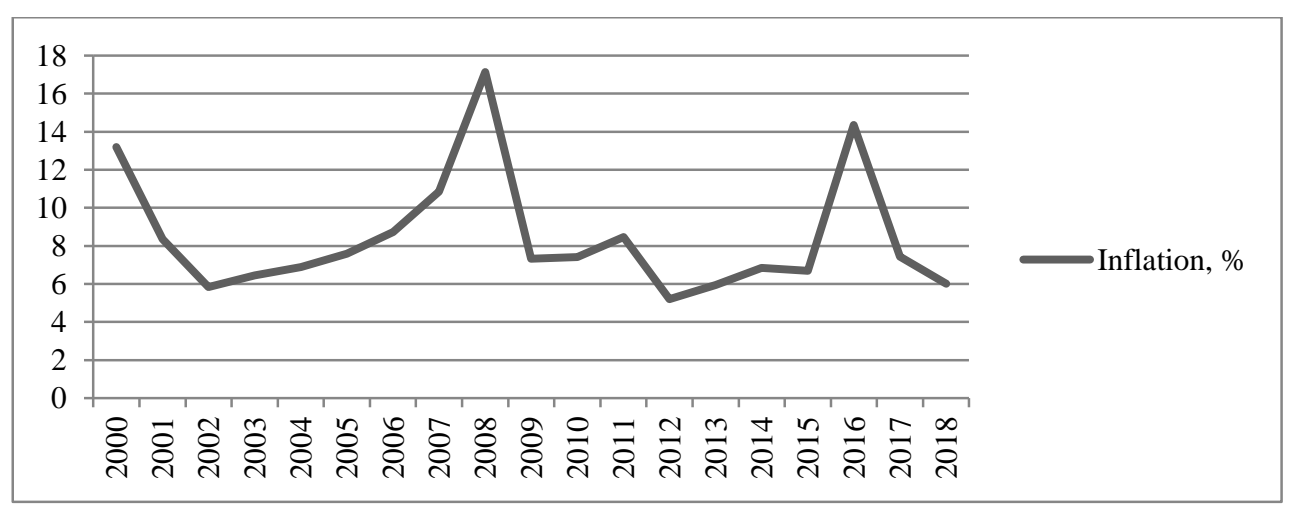

Note: Compiled by the author on the base of World Bank DataBase

Fig. 1. Dynamics of inflation rate in Kazakhstan (2000-2018) [12].

To identify the relationship between changes in inflation and GDP, a regression analysis method was used. As a result, the following model was obtained (Table 1):

$$
\begin{gathered}
\wedge \mathrm{GDP}+\mathrm{USD}=-4.1558 \mathrm{x}+156.46 \\
\mathrm{~T}=19, \mathrm{R}^{\wedge} 2=0.033
\end{gathered}
$$

Table 1. Linear regression analysis. 


\begin{tabular}{|c|c|c|c|c|c|c|}
\hline \multicolumn{2}{|c|}{ Regression Statistics } & & & & & \\
\hline Multiple R & 0,181746 & & & & & \\
\hline R Square & 0,033032 & & & & & \\
\hline $\begin{array}{l}\text { Adjusted R } \\
\text { Square }\end{array}$ & $-0,02385$ & & & & & \\
\hline $\begin{array}{l}\text { Standard } \\
\text { Error }\end{array}$ & 74,12173 & & & & & \\
\hline Observations & 19 & & & & & \\
\hline \multicolumn{7}{|l|}{ ANOVA } \\
\hline & $d f$ & $S S$ & $M S$ & $F$ & Significance $F$ & \\
\hline Regression & 1 & 3190,487 & 3190,487 & 0,580719 & 0,456474 & \\
\hline Residual & 17 & 93398,53 & 5494,031 & & & \\
\hline \multirow[t]{2}{*}{ Total } & 18 & 96589,02 & & & & \\
\hline & Coefficients & $\begin{array}{l}\text { Standard } \\
\text { Error }\end{array}$ & $t$ Stat & $P$-Value & Lower 95\% & $\begin{array}{c}\text { Upper } \\
95 \%\end{array}$ \\
\hline Intercept & 156,4632 & 49,13766 & 3,184181 & 0,005429 & 52,7918 & 260,1346 \\
\hline $\mathrm{X}$ Variable 1 & $-4,15577$ & 5,453419 & $-0,76205$ & 0,456474 & $-15,6615$ & 7,349936 \\
\hline
\end{tabular}

A regression coefficient of -4.1558 shows an inverse relationship between GDP change and inflation, but the determination coefficient is very small and shows that only $0.33 \%$ of GDP dynamics depends on changes in inflation, and $99.7 \%$ of GDP depends on unexplained factors (Figure 2). The significance of the regression model is very low, since the fraction of the factor is much lower than the proportion of residual variance.

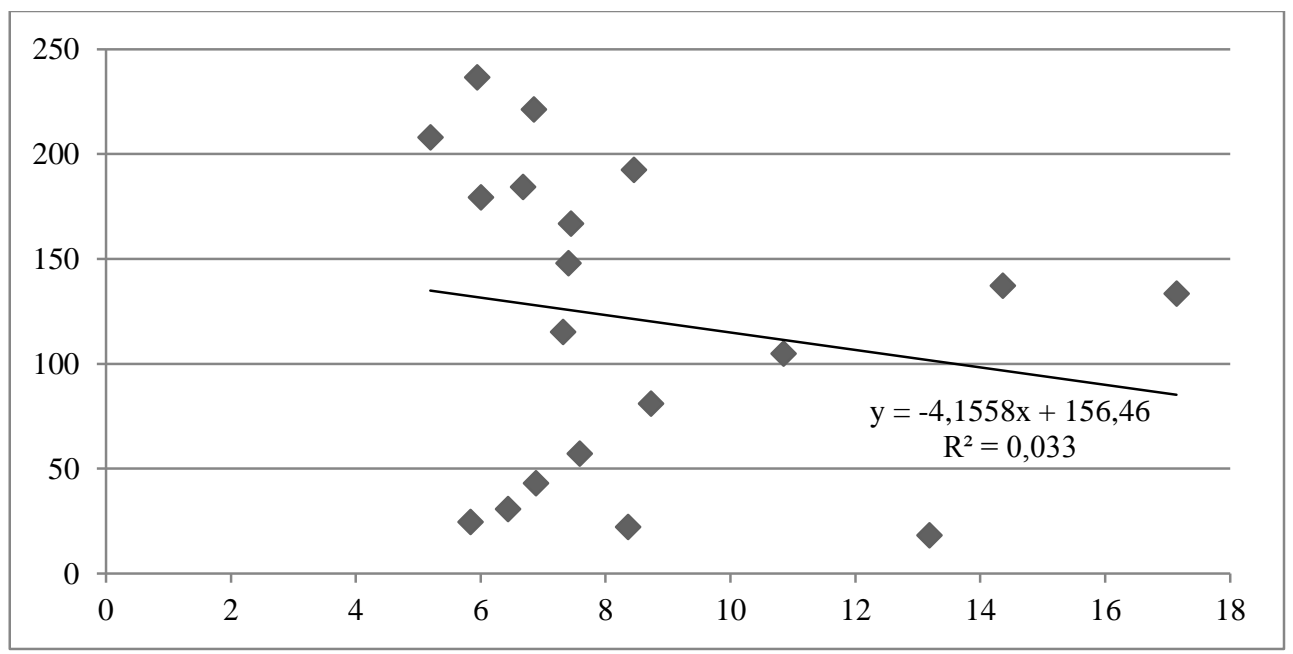

Note: Compiled by the author

Fig. 2. Correlation field of GDP and inflation rate in Kazakhstan (2000-2018).

Thus, based on real empirical data using econometric calculations, we determined the insignificant effect of inflation on economic growth rates. 
This means, before pursuing a policy of containing inflation, it is necessary to identify the impact of this indicator on the main macroeconomic variables and determine the threshold level of inflation for the domestic economy, and then determine effective monetary policy instruments. Unfortunately, the monetary authorities do not provide sufficiently substantiated indicators of the critical level of inflation for Kazakhstan, however, they are actively pursuing an inflation targeting policy.

Inflation targeting refers to a monetary policy regime under which the following conditions are met: 1) the central bank publishes publicly the medium-term inflation targets that it intends to achieve; 2) price stability is recognized as the primary goal of monetary policy; 3 ) the decision-making scheme for setting specific parameters for DCT instruments includes more information than just the exchange rate or monetary aggregates (labor market indicators, fiscal policy, real and nominal interest rates, etc. are taken into account); 4) the monetary authorities constantly inform the public about their decisions and their reasons; 5) the monetary authorities are responsible to society for obligations related to the achievement of inflation targets.

Until the 2000s, the monetary policy of the National Bank of the Republic of Kazakhstan consisted in the application of the monetary targeting regime. Despite the great effectiveness of monetary policy under this regime, there was no direct relationship between changes in the monetary base and inflation. From that moment, a long period of preparation for the policy of the National Bank of the Republic of Kazakhstan for the inflation targeting regime began.

On August 20, 2015, the Government and the National Bank of Kazakhstan announced the implementation of a new monetary policy based on the inflation targeting regime and the abolition of the currency corridor and the transition to a free-floating exchange rate. The tool for implementing the inflation targeting regime was the base rate. The transition to such a monetary policy was not well thought out, from the point of view of the consequences on the whole economy of the country. At that time, there was a lot of scientific work substantiating the unacceptability of the inflation targeting regime with a floating exchange rate policy for countries that are not issuers of world reserve currency. In particular, the Russian economist S. Glazyev explains that it is impossible to keep the exchange rate with interest rates alone, and that such a policy is favorable only for speculators [13]. These conclusions were confirmed in reality by the example of the economy of Kazakhstan.

The National Bank of Kazakhstan on September 2, 2015 introduced a base rate within $17 \%$. to one-day repos, refusing to establish targets for the exchange rate and to control the movement of the capital account. As a result of speculative attacks, by September 16, the tenge exchange rate fell from 230 to 350 tenge per dollar. And after November 6, 2015, the base rate ceased to exist at all, i.e. from this day, the National Bank ceased to provide money to banks, regardless of the interest rate. The demand for liquidity was satisfied at the interbank auction, which led to strong fluctuations in the yield on one-day repos and an increase in the interest rate to $200 \%$.

If interest rates for one-day loans have increased significantly, this means only one thing, that banks, under the influence of devaluation expectations, conducted speculative operations in the foreign exchange market in order to get the maximum benefit. It was also absurd to expect that the base rate could affect the interest rate on bank loans. In the balance sheet of banks increased cash assets, and the number of loans issued decreased. In addition, one of the conditions for introducing the inflation targeting regime is the absence of public debt and the stability of the financial sector to external shocks. These conditions in Kazakhstan are not feasible today, due to the raw material orientation of the economy and the constant deficit of the state budget. At the same time, the inflation targeting regime is effective in the case of monetary reasons for inflation; in our case, inflation of costs caused by the increase in production costs due to the devaluation of the national currency is presented. 
Along with this, demonetization of the economy can be traced in Kazakhstan. Despite the fact that over the past period the money supply has increased significantly, for example, in 2015 the level of monetization of the economy grew by $15 \%$ compared to 2000 and became equal to $43 \%$ in 2015 , this figure is much lower than in developed countries. The monetization index defines the function of money as a means of servicing production relations. This means that in order to create conditions for sustainable economic growth, it is necessary to increase the level of monetization, which is expressed by the Marshall coefficient. The Marshall coefficient is considered a significant index, with which you can determine the development of the financial sector [14]. In Kazakhstan, it is calculated as the ratio of the M3 monetary aggregate to GDP. In developed countries, it exceeds $150 \%$, while in Kazakhstan, the monetization rate fluctuates at $40 \%$ (Figure 3). This is due to the fact that in the recent history of the Kazakhstani economy, economic instability was observed against the background of low confidence in the national currency. As a result, there is a high tendency to keep deposits in foreign currency and a high share of money storage in the form of cash. All these factors became the reason that the money supply - M3 is much less than the country's GDP.

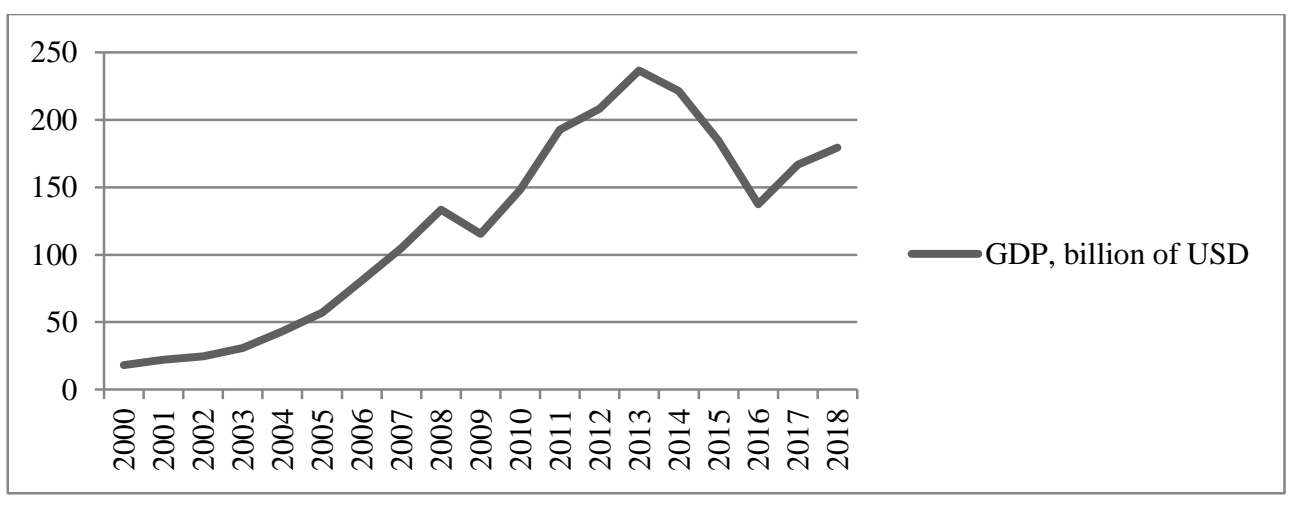

Note: Compiled by the author on the base of World Bank DataBase

Fig. 3. Dynamics of GDP in Kazakhstan (2000-2018) [12].

Given all of the above factors, net inflation targeting can lead to high inflation, as well as high exchange rate volatility, which ultimately negatively affects long-term economic growth. This effect is especially significant for countries in which the reputation of central banks is not high enough, which does not allow managing inflation expectations in the context of discretionary policies.

Therefore, subsequently, the National Bank of the Republic of Kazakhstan abandoned the policy of a floating exchange rate and switched to a regulated rate through interventions in the foreign exchange market. The monetary policy regime, in which, in addition to inflation, the central bank also includes the exchange rate, is called a hybrid (or mixed) inflation targeting. This policy made it possible to stabilize the situation in the money market and again to introduce a base rate from the beginning of 2016.

In his work, Kartaev (2017) also substantiated the effectiveness of such a monetary policy; I analyze the data on the economy of 176 countries. He concluded that managing the exchange rate under the inflation targeting regime better stimulates economic growth compared to pure inflation targeting (not involving foreign exchange intervention) [15].

The official documents of the National Bank of the Republic of Kazakhstan indicate that the target benchmark for the inflation rate is 3-4\% until the current 2020. The choice of such 
a parameter of the nominal anchor is not justified by the monetary authorities. Indeed, as we have already established for Kazakhstan, the threshold level of inflation is not defined, and the value of threshold inflation equal to 3-4\% corresponds only to developed countries, for countries such as Kazakhstan this indicator is much higher. The suppression of inflation below a critical level, where inflation has basically taken on the character of cost inflation, overcoming which requires non-monetary methods, can lead to a reduction in production, an increase in unemployment and a long-term economic downturn.

Earlier, M. Bruno in [16] showed that with high inflation, economic growth is possible at a fairly high rate. The calculations of other economists showed that countries that for a long time pursued a tight monetary policy were faced with a decline in economic growth. So, in France, the average annual GDP growth rate for the entire period was about $2.4 \%$, in Germany $-2.4 \%$, Japan $-3.9 \%$, England - less than $2 \%$, in the USA - $2.3 \%$. Of the developed countries, the exception is South Korea, where this indicator for the period under review amounted to $8.8 \%$. Among developing countries, the average annual GDP growth rate is significantly higher. So, in Brazil they amounted to $3.8 \%$, India - 5\%, Malaysia - about $8 \%$. Economic policy, for example, in Brazil was deliberately aimed at maintaining high inflation as a kind of fuel for the real sector of the economy. According to the law of supply, the higher the price of the goods, the greater the desire of sellers to produce and sell their goods on the market. It follows that maintaining inflation at moderate or threshold limits stimulates economic growth. This largely depends on economic policy, where the main goal is economic growth, and not just suppression of inflation. The present research enables us to identify and analyse problems of formation and development of Kazakhstan's industrial and innovative economy, namely the lack of application of research results in business, inadequate and ineffective funding (both public and private) of innovation activities, as well as little support and encouragement for scientists as major participants in innovation activities $[17,18,19]$.

\section{Conclusion}

Thus, in modern conditions of a complex system of monetary circulation, when it is constantly changing under the influence of external and internal factors, monetary policy should be comprehensively verified and pursue the goal of long-term economic growth. Any changes in monetary policy should be based on comprehensive basic research. Research on the nature, significance and consequences of inflation should be relevant. In our opinion, a necessary condition for conducting an optimal monetary policy is the determination of threshold inflation for Kazakhstan. In this case, the values of the current and threshold inflation rates $\rho$ and $\rho *$ will become the main indicators, can objectively signal the accumulation of negative consequences of the current monetary policy and the need to adjust it to prevent an economic downturn and ensure sustainable growth.

\section{References}

1. I. Nekrasova, Y.Fomenko, International Research Journal, 8 (39), 56-60 (2015)

2. D. Kunasheva, Bulletin of KazEU, 2, 59-62 (2017)

3. A. Nurzhigitova, Young scientist, 13, 481-482 (2016)

4. A. Illarionov, Problems of Economics, 10 (1998)

5. J. Stiglitz, Bulletin of ECAAR, 16 (2013)

6. J. Akerlof, Ecovest, 4 (2), 188-228 (2004)

7. K. Berentayev, S. Asylkhanova, Macroeconomic stabilization and conditions necessary for the subsequent recovery of the economy of the Republic of Kazakhstan.Alpari, 2

8. V. Polterovich, Economic science of modern Russia, 2, 40-49 (2006) 
9. R. Espinoza, H. Leon, A. Prasad, IMF Working Paper, 10, 76, (2010)

10. S. Kremer, A. Bitsk, D. Nautz, Empirical Economics, 44 (2), 861-878 (2013)

11. E. Khan, M. Khan, Studies in the field of economics, 68 (2), 133-143 (2014)

12. World Bank, Data Base on Consimer Price Index and GDP (Current US\$) for 20002018 (2019)

13. S. Glazyev, Economic Issues, 9 (2015)

14. I. Grekov, On improving approaches to determining the monetization of the economy and the rationale for its optimal level (Finance and Credit, 2007)

15. F. Kartaev, Economic Issues, 2, 62-74 (2017)

16. M. Bruno, Economic Issues, 9 (2016)

17. K. Mukhtarova, S. Ziyadin, S. Kupeshova, \& R. Doszhan, Economic Annals-XXI, 168 (11-12), 38-43 (2017). DOI: 10.21003/ea.V168-08

18. S. Ziyadin, R. Doszhan, A. Borodin, A. Omarova, \& A. Ilyas, E3S Web of Conferences, 135, 04022 (2019) DOI: 10.1051/e3sconf/201913504022

19. S. Ziyadin, A. Omarova, R. Doszhan, G. Saparova, \& G. Zharaskyzy, Problems and perspectives in management, 16(4), 331-343 (2018). DOI: 10.21511/ppm.16(4).2018.27 